DOI 10. 18307/2019. 0313

(C) 2019 by Journal of Lake Sciences

\title{
一株耐冷异养硝化菌的分离鉴定及脱氮特性”
}

\author{
周英萍, 唐美珍**, 曹彦雪, 周高洁, 陈娟娟, 马文秀 \\ (曲阜师范大学南四湖湿地生态与环境保护重点实验室,曲阜 273165)
}

\begin{abstract}
摘 要: 利用异养硝化培养基, 冬季从南四湖人工湿地底泥中分离篮选到一株具有较高脱氮性能的菌株 Z01. 经形态特 征、生理生化特性以及 $16 \mathrm{~S}$ rDNA 序列分析, 初步鉴定该菌株为假单胞菌属 (Pseudomonas sp.), 命名为 Pseudomonas sp. Z01. 实验探究得到菌株 Z 01 的最佳初始投菌量为 7\%, 最适温度、 $\mathrm{pH}$ 和盐度分别为 $15^{\circ} \mathrm{C} 、 6.0 \sim 8.0$ 和 $0.3 \%$, 最佳碳源为葡 萄糖. 在最适生长条件下, 通过氨氮去除试验发现该菌株对模拟污水中氨氮的去除率有一定提高, 是异养硝化培养基中 氨氮去除效率的 1.1 倍. 此外, 该菌株对模拟废水中总氮和 COD 也具有较好的去除效果. 研究表明, 菌株 Z01 在冬季污水 处理中硝化脱氮具有良好的应用前景和很大的发展空间.
\end{abstract}

关键词：低温异养硝化;生物脱氮;菌株;氨氮;南四湖

\section{Isolation and denitrification characteristics of a psychrotrophic and heterotrophic nitrification bacterium}

ZHOU Yingping, TANG Meizhen ${ }^{* *}$, CAO Yanxue, ZHOU Gaojie, CHEN Juanjuan \& MA Wenxiu

(Key Laboratory of Nansi Lake Wetland Ecosystem \& Environment Protection, Qufu Normal University, Qufu 273165, P.R. China)

Abstract: A heterotrophic nitrifying bacteria strain Z01 was isolated from the sediment of Lake Nansi constructed wetland in winter, and it was studied for its capacity of nitrification and nitrogen removal. Methods of morphological, physiological and biochemical were used to identify strain Z01 as well as $16 \mathrm{~S}$ rDNA analysis. It is affiliated to be Pseudomonas sp., which named Pseudomonas sp. Z01. These data showed that the optimum dosage, temperature, $\mathrm{pH}$ and salinity of microbial strains $\mathrm{Z01}$ were $7 \%, 15^{\circ} \mathrm{C}, 6.0-$ 8.0 and $0.3 \%$, as sucrose as optimum carbon. Under the optimum removal efficiency of ammonia nitrogen from simulated wastewater by strain 10 was 1.1 times higher than that of heterotrophic nitrification medium. Moreover, it was better on the removal performance of the total nitrogen and COD in the simulated wastewater. Therefore, strain Z01 has a good application prospect and great development space in nitrification denitrification of sewage treatment in winter.

Keywords: Low temperature heterotrophic nitrification; biological denitrification; strain; ammonia nitrogen; Lake Nansi

近几十年来,随着我国经济发展和城市化速度的加快,氮、磷等营养元素的排放导致水体富营养化进程 不断加剧,其中氨氮浓度过高是造成水体富营养化的主要原因之一 ${ }^{[1]}$. 废水异养硝化脱氮是对传统硝化理 论的丰富与突破, 也是目前水处理领域中关注和研究的热点 ${ }^{[2-3]}$. 异养硝化菌由于具有世代周期短、生长速 率快、环境耐受能力强等特点 ${ }^{[4-6]}$, 其在某些环境之中的异养硝化作用贡献可与自养菌相当，甚至更大 ${ }^{[7]}$. 目前, 一些异养硝化菌也逐渐被笁选出来, 例如假单胞菌 (Pseudomonas alcaligenes) ${ }^{[8]}$ 、粪产碱菌 (Alcaligenes faecalis $)^{[9]}$ 、木糖氧化无色杆菌 (Achromobacter xylosoxidans $)^{[10]}$ 等.

低温微生物是极端微生物之一, 它们有着独特的生理功能以适应环境, 研究这类微生物不仅具有重要 的理论意义,而且在实际推广应用中产生了显著的经济效益和环境效益 ${ }^{[11]}$. 但低温微生物在生活环境中要

* 2017 年曲阜师范大学国家级大学生创新创业训练计划项目 (201710446074) 和国家自然科学基金项目 (31700433, 31672314 ) 联合资助. 2018-10-17 收稿; 2018-11-13 收修改稿. 周英萍(1995 ), 女, 本科; E-mail: qfzyp951022@ 163.com.

** 通信作者;E-mail:qsd_tmzh@mail.qfnu.edu.cn. 
比中温微生物少, 靠自然选择很难形成优势菌群, 人工篮选、培育低温优势菌是扩大菌群的最佳途径. 国内 外对低温脱氮微生物已有一些研究, 但都存在一定缺陷: 1) 温度偏高, 接近常温菌, 如问法军等 ${ }^{[12]}$ 从刺参养 殖池塘环境中驯化分离篎选到一株低温有机物和氨氮降解菌株 DB 11 , 其对 $1 \sim 20 \mathrm{~g} / \mathrm{L}$ 质量浓度的刺参饵料 液中 $\mathrm{NH}_{3}-\mathrm{N} 3 \mathrm{~d}$ 的去除率达 $91.7 \% \sim 99.9 \%$, 但该菌培养温度为 $15^{\circ} \mathrm{C}$. 赵燕 ${ }^{[13]}$ 从青藏高原冰川冻土中分离纯 化得到 A1、A4、A6 3 株低温菌, 其对氨氮的去除率在 58\% 70\% 之间,但该菌培养温度为 $16^{\circ} \mathrm{C} .2$ ) 分离篮选 的普通耐低温菌 (并非专门的低温硝化或反硝化脱氮菌) 对普通低氮废水具有一定低温脱氮效率菌, 但对含 氮高的低温废水脱氮效率就难以保证, 如 Chevalier ${ }^{[14]} 2000$ 年从南极和北极成功分离到 4 株耐冷丝状蓝细 菌, 该菌在低温环境条件下对氮和磷有较高的去除率. 徐巧等 ${ }^{[15]}$ 从寒冷地区水土样品中在 $2^{\circ} \mathrm{C}$ 下分离到一 株耐冷型低温微生物, 在 $5^{\circ} \mathrm{C}$ 下对氨氮的去除率达 $90 \%$. 冬季寒冷的气候条件致使污水处理系统中微生物 数量减少, 微生物对营养物质的转运减慢, 吸收减少, 对蛋白质合成速率降低, 生命代谢活动减缓等 ${ }^{[16]}$, 从而 导致冬季低温条件下生物脱氮效率大大降低. 因此, 从低温自然环境中分离、篮选出对含氮化合物具有较高 代谢活性的耐冷型脱氮菌是提高寒冷地区低温季节氮污染水体原位生物修复效果的根本途径和有效 措施 ${ }^{[17]}$.

本研究从冬季南四湖底泥中经驯化、分离和纯化得到一株能在低温及好氧条件下进行高效硝化的菌 株,利用生物信息学方法对其进行鉴定,并对菌株的脱氮性能进行了分析, 为其将来应用于冬季低温污水的 生物脱氮提供了理论依据和菌种资源.

\section{1 材料与方法}

\section{1 材料}

1.1.1 菌种来源 2016 年 12 月- 2017 年 1 月 (冬季),在山东省南四湖新薛河人工湿地中采用柱状法采集表 层 $0 \sim 20 \mathrm{~cm}$ 泥样, 放人已事先灭菌的样品袋中, 编号, 于 $4^{\circ} \mathrm{C}$ 便携式冰箱中保存. 湿地表层土壤温度为 $4 \sim 6^{\circ} \mathrm{C}$.

1.1 .2 培养基 富集培养基 $(\mathrm{pH}=7.0)$ : 用于异养硝化菌的富集培养; 异养硝化培养基 $(\mathrm{pH}=7.0)$ : 用于异养 硝化菌的分离纯化及脱氮特性研究; 牛肉膏蛋白胨培养基 $(\mathrm{pH}=7.2)$ : 用于菌株的形态观察、保存及活化. $\mathrm{LB}$ 培养基: 唯一碳源基础培养基, 碳源物质(葡萄糖、柠檬酸钠、乙酸钠、蔗糖、可溶性淀粉). 各培养基的具体配 置方法参考《微生物学实验教程》 ${ }^{[18]}$.

1.1.3 模拟污水配方 模拟污水以葡萄糖为碳源、氯化铵为氮源、磷酸二氢钠为磷源, 并添加适量的微量元 素, 使 $\mathrm{C}: \mathrm{N}: \mathrm{P}=100: 5: 1^{[15]}, \mathrm{COD}$ 、氨氮、总磷的初始浓度分别约为 $1000 、 50$ 和 $10 \mathrm{mg} / \mathrm{L}, \mathrm{pH}$ 为 7.0.

\section{2 方法}

1.2.1 耐冷异养硝化菌的分离管选 将所采集的泥样放人 $4^{\circ} \mathrm{C}$ 低温培养箱中培养驯化 $5 \mathrm{~d}$, 取驯化后的泥样 1 $\mathrm{g}$ 接人事先已灭菌, 内装玻璃珠和 $100 \mathrm{ml}$ 富集培养液的三角瓶中,于 $6 \sim 8^{\circ} \mathrm{C}$ 下振荡培养 ( 160 转 $\left./ \mathrm{min}\right) 3 \mathrm{~d}$, 使 微生物快速生长, 达到富集的作用. 将上述菌液接于无菌水中进行稀释处理, 分别得到 $10^{-6} \sim 10^{-1}$ 倍的稀释 液. 选取 $10^{-6} \sim 10^{-4}$ 倍的培养液各 $1 \mathrm{ml}$, 采用平板涂布法分别接种于异养硝化固体培养基平板上(设置 3 个 平行), 放人 $6 \sim 8{ }^{\circ} \mathrm{C}$ 培养箱中培养并记录各平板菌株的生长状况. 从中篮选出长势较好的 24 株菌株用平板 划线的方法反复分离纯化直至获得单菌落, 将单菌落接种到试管斜面培养基上, 编号为 $\mathrm{Z} 01 \sim \mathrm{Z} 24$, 于 $4^{\circ} \mathrm{C}$ 冰 箱内保存.

1.2.2 菌种的初篎与复篮 将分离出的 24 株单菌落分别接种于 LB 培养基中 $6 \sim 8^{\circ} \mathrm{C}$ 振荡培养 ( 160 转 $/ \mathrm{min}$ ) 至 $\mathrm{OD}_{600}$ 为 1.0 左右时, 在 $4^{\circ} \mathrm{C} 、 1200$ 转 $/ \mathrm{min}$ 下离心, 弃去上清液, 收集菌体细胞, 加生理盐水摇匀, 再离心, 如 此反复 3 次, 以消除菌体携带的营养组分. 然后用生理盐水调整菌体浓度, 使其 $\mathrm{OD}_{600}$ 值在 $0.8 \sim 1.0$ 左右, 备用.

将上述制备好的菌悬液以 $10 \%$ 的接种量接于异氧硝化培养基中, $6 \sim 8^{\circ} \mathrm{C}$ 振荡培养 $(160$ 转 $/ \mathrm{min}$ ) $3 \mathrm{~d}$, 离 心, 取等量上清液滴加 $1 \mathrm{ml}$ 纳氏试剂, 根据其颜色显示情况, 最终选 5 株颜色最浅的编号 Z01、Z05、Z13、 Z20、Z23 菌株进行复篮.

将初篮所得菌种按上述方法制备菌悬液, $10 \%$ 的接种量接于异氧硝化培养基中, $6 \sim 8^{\circ} \mathrm{C}$ 振荡培养 $(160$ 
转 $/ \mathrm{min}$ ), 并每间隔 $12 \mathrm{~h}$ 测量培养基中菌悬液的 $\mathrm{OD}_{600}$ 和氨氮浓度, 计算出各菌株生长情况及氨氮去除率, 笁 选出氨氮去除率最好的菌株 Z 01 进行进一步的研究实验.

1.2.3 菌种的鉴定 肉眼观察菌落特征后, 将菌株 Z01 染色并通过显微镜观察, 记录其形态特征, 再结合它的 生理生化特性进行初步鉴定 ${ }^{[19-20]}$.

扫描电镜观察: 将纯化好的菌株 Z01 转接至 LB 固体培养基, 在 $30^{\circ} \mathrm{C}$ 无菌条件下培养 $24 \mathrm{~h}$ 左右. 挑取菌 株 Z 01 , 以无菌水洗涤多次. 菌体先用 3\% 的戊二醛固定, 漂洗, 再用 $1 \%$ 的锇酸固定, 最后用乙醇脱水. 临界 点干燥, 粘台, 喷金, 在扫描电子显微镜下观察.

16S rDNA 序列分析: 菌株 Z01 经培养后提取总 DNA, 以此为模板, 采用引物 8f 5'AGAGTTTGATCCTGGCTCAG 3' 20 bp 和 1492r 5' GGTTACCTTGTTACGACTT 3' 19 bp, 将 PCR 产物克隆后由上海生工生物工程 有限公司进行纯化鉴定.

1.2.4 生长条件探究 生长曲线测定: 将菌株 Z01 活化培养 $24 \mathrm{~h}$ 后按 $10 \%$ 的接种量接种到异氧硝化液体培 养基中, 设置 3 个平行, 在 $6 \sim 8^{\circ} \mathrm{C}$ 振荡 $\left(160\right.$ 转 $/ \mathrm{min}$ ) 培养, 每 $2 \mathrm{~h}$ 取样测定 $\mathrm{OD}_{600}$ 值, 以平均值绘制生长曲线.

硝化特性探究: 将菌株 Z01 接种到装有 $100 \mathrm{ml} \mathrm{LB}$ 液体的培养基中, $6 \sim 8^{\circ} \mathrm{C}$ 振荡 ( 160 转 $/ \mathrm{min}$ ) 培养至达 到对数生长期 $\left(\mathrm{OD}_{600}\right.$ 为 1.0 左右) 作为菌种. 离心, 用生理盐水冲洗 $2 \sim 3$ 次, 再用生理盐水稀释至菌悬液 $\mathrm{OD}_{600}$ 为 1.0 , 备用.

将制备好的菌种 Z01 按 1\% 15\% 的接种量接种到 $100 \mathrm{ml}$ 异氧硝化液体培养基中, 在 $6 \sim 8^{\circ} \mathrm{C}$ 振荡 ( 160

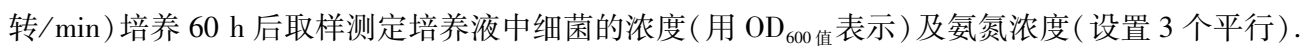

其他条件探究如下: $\mathrm{pH}$ 分别设置为 $1 、 3 、 5 、 6 、 7 、 8 、 9$ 和 10 ; 盐度分别设置为 $0 、 0.1 \% 、 0.3 \% 、 0.5 \% 、 1 \%$ 、 $3 \%$ 和 $5 \%$; 碳源分别为乙酸钠、葡萄糖、柠檬酸钠、淀粉、蔗糖; 温度分别为 $4 、 6 、 10 、 15 、 20 、 25$ 和 $35^{\circ} \mathrm{C}$; 菌的投 加量为最佳投菌量 (每个条件设置 3 个平行).

1.2.5 菌株 Z01 对模拟污水的净化按照探究出的最适生长条件, 对菌株 Z01 再次进行模拟废水去除实验, 测量计算出其对氨氮和总氮的去除效率, 与实验初期的去除效率比较,得出更加全面的实验结论.

1.2.6 水质指标的测定 氨氮的测定采用纳氏试剂分光光度法, 具体操作步骤详见《水和废水监测分析方

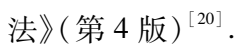

\section{2 结果与讨论}

\section{1 耐冷硝化菌株的篮选}

经富集分离出的 24 株单菌在异氧硝化培养基中 $6 \sim 8^{\circ} \mathrm{C}$ 振荡培养 ( 160 转/ $\min$ ) $3 \mathrm{~d}$ 后, 其上清液滴加纳 氏试剂的颜色变化结果见表 1 .

从表 1 可见,Z01、Z05、Z13、Z20 和 Z23 的上清液滴加纳氏试剂后形成的黄棕色最浅 (表 1). 因为氨与纳 氏试剂发生反应后生成黄棕色胶体化合物, 氨浓度愈高,生成化合物的颜色愈浓. 因此选择 Z01、Z05、Z13、 Z20 和 Z23 5 株菌进行进一步的复篮, 5 株菌在异氧硝化培养基中的生长情况及氨氮去除率随时间的变化关 系如图 1 .

表 1 滴加纳氏试剂后上清液显色情况

Tab.1 Coloration of the solution after a drop of Ghana's reagent

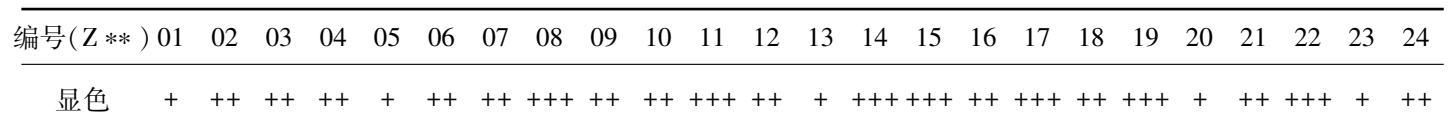

+表示颜色深度.

由图 1a 可以看出, 菌株 Z01、Z05、Z13、Z23 在 24 50 h 内生长旺盛, 繁殖迅速, 处于对数期阶段, $60 \mathrm{~h}$ 后 菌株生长逐渐进人稳定期, $\mathrm{OD}_{600}$ 趋于稳定. 菌株 $\mathrm{Z} 20$ 溶液的 $\mathrm{OD}_{600}$ 最小, 生长量最低, 其原因可能是菌株 $\mathrm{Z} 20$ 菌体细胞相互聚集在一起形成絮状沉淀, 导致菌溶液中菌含量少, 也可能是菌株 Z20 在生长过程中产生了 一定量的沉淀分泌物, 所以菌溶液 $\mathrm{OD}_{600}$ 测定值较小. 由各菌株生长情况可以看出, 该 5 株耐冷异氧硝化菌 进入稳定期的时间虽然比常温的异养硝化菌长 ${ }^{[21]}$, 但比其他耐冷硝化菌生长更迅速 ${ }^{[22]}$. 
由图 $1 \mathrm{~b}$ 可以看出, 在培养 $0 \sim 60 \mathrm{~h}$ 之间,随着培养时间的延长, 5 株菌对氨氮的去除率都呈上升的趋势, 并于培养 $60 \mathrm{~h}$ 左右达到最大值; $60 \mathrm{~h}$ 后各菌株氨氮去除率的变化幅度很小, 基本趋于稳定. 因此选取 $60 \mathrm{~h}$ 时 5 株菌株的氨氮去除率作进一步的具体分析.

对比 5 株菌在培养 $60 \mathrm{~h}$ 时对异氧硝化培养基中氨氮的去除率: 菌株 Z01 的氨氮去除率最高, 其去除率 高达 83.51\% ; 菌株 Z05、Z13、Z20、Z23 的氨氮去除率基本一致,无显著差异,其去除率为 65.34\% 67.91\% (图 $1 \mathrm{~b})$. 因此,本实验最终选定菌株 Z01 做进一步的研究.
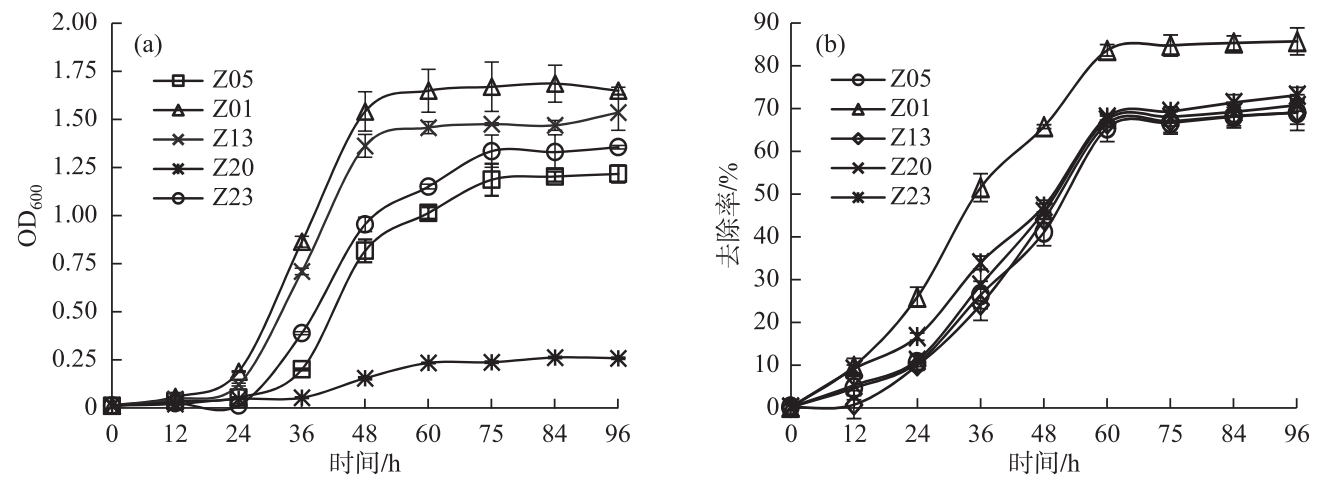

图 15 株菌株的生长量 $(\mathrm{a})$ 和氨氮去除率 $(\mathrm{b})$

Fig. 1 The growth (a) and $\mathrm{NH}_{3}-\mathrm{N}$ removal rate (b) of five strains

\section{2 菌株鉴定}

2.2.1 形态学和生理生化鉴定 将篮选出的菌株 Z01 进行形态观察及生理生化试验, 在 $6 \sim 8^{\circ} \mathrm{C}$ 下培养, 菌株 Z01 表现为表面光滑、湿润,边缘较整齐,圆形凸起,不透明的圆形白色菌落. 革兰氏染色试验菌株 Z01 呈阴 性, 扫描电镜下观察为短杆状, 表面光滑无分泌物, 大小为 $(0.6 \sim 0.8) \mu \mathrm{m} \times(1.1 \sim 1.4) \mu \mathrm{m}$ (图 2). 根据伯杰 氏系统细菌学手册 ${ }^{[23]}$ 对菌株 Z01 进行生理生化试验, 其结果见表 2.
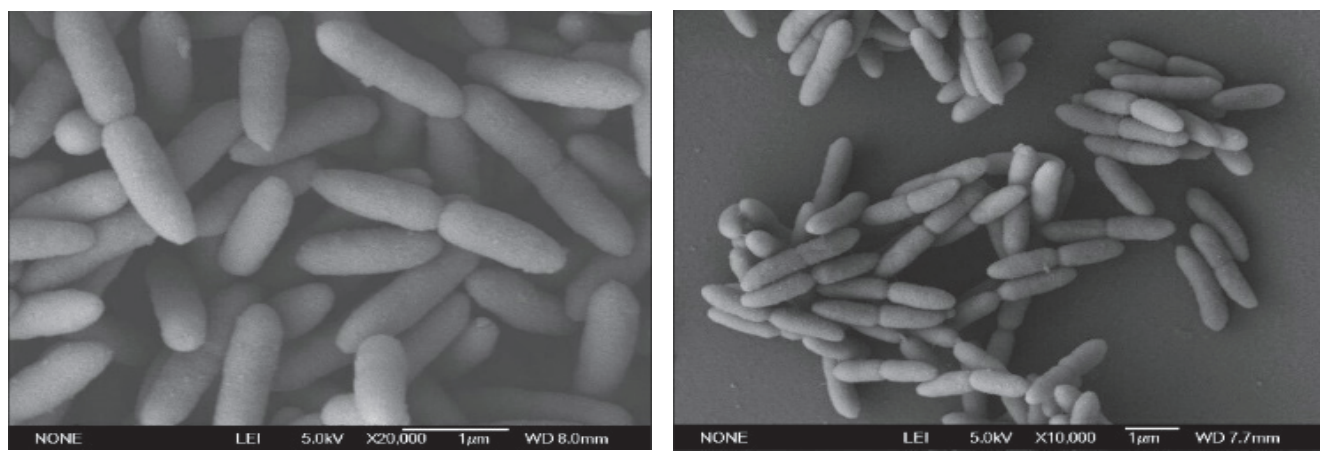

图 2 菌株 Z01 的扫描电镜图

Fig. 2 SEM of strain Z01

2.2.2 菌株 Z01 的 $16 \mathrm{~S}$ rDNA 序列分析 将送交上海生工生物工程技术服务有限公司测菌株 Z01 的 $16 \mathrm{~S}$ rDNA 序列通过 BLAST 检索 GenBank 中的核酸序列进行同源性比对, Clustal W 和 PHYLIP 软件分析并构建 了进化树(图 3).

菌株 Z01 的 16S rDNA 特异序列为 1385bp (GenBank 接受号为 MH220796)，与多株 Pseudomonas sp. 16S rDNA 序列的相似性达 $99 \%$ 以上. 结合菌株的形态学及生理生化试验结果, 可确定菌株 Z01 为假单胞菌属 Pseudomonas sp., 命名为 Pseudomonas sp. Z01. 
表 2 菌株 Z01 的生理生化特性

Tab.2 Physiological characteristics of the bacterial strain Z01

\begin{tabular}{cccc}
\hline 鉴定项目 & 菌株 Z01 & 鉴定项目 & 菌株 Z01 \\
\hline 革兰氏染色 & - & G 氧化发酵试验 & + \\
明胶水解 & + & 甲基红试验 & - \\
接触酶试验 & + & 柠檬酸盐试验 & + \\
尿素水解试验 & - & 产氨试验 & - \\
硝酸盐还原试验 & - & 硝酸盐为唯一氮源 & + \\
\hline
\end{tabular}

“+”为阳性;“一”为阴性.

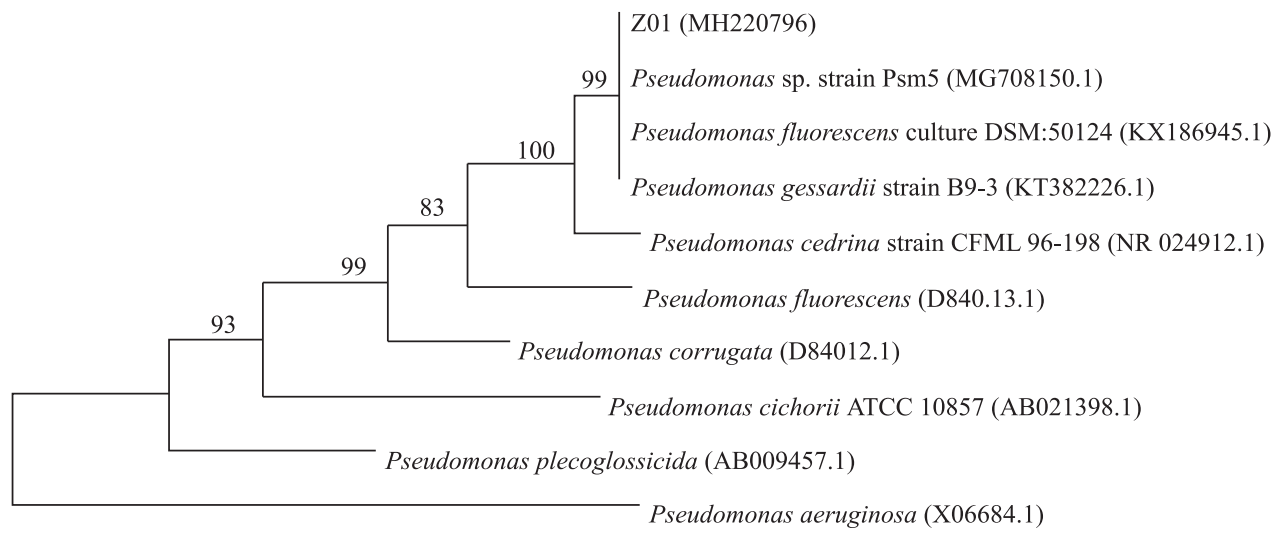

图 3 菌株 Z01 的系统进化树

Fig.3 Phylogenetic tree of the bacterial strain Z01

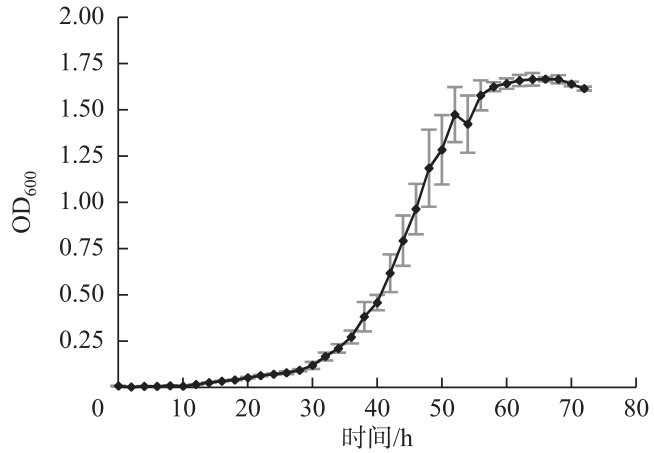

图 4 菌株 Z01 的生长曲线

Fig.4 The growth curve of strain Z01

\section{3 菌株 Z 01 的生长曲线}

从菌株 Z $\mathrm{Z} 01$ 的生长曲线可以看出, 在最初的 $30 \mathrm{~h}$ 内菌株生长相当缓慢, 处于生长延滞期. 之后, 随着培 养时间的延长, 菌株的生长速度明显加快, 并于 $60 \mathrm{~h}$ 左 右达到最大值, $60 \mathrm{~h}$ 后菌株逐渐进人稳定期 (图 4). 因 此, 根据菌株的生长曲线, 结合前面所做的菌株对废水 去除效果的实验结果, 可以大致确定后期实验所需菌 种的培养时间约为 $60 \mathrm{~h}$, 因为此时菌株的生长速率最 大, 其生物活性最高, 对废水各个指标的去除率相对 最好.

\section{4 菌株 Z01 硝化特性研究}

接种量的大小决定了菌株的繁殖速度及数量, 从 而直接影响污水中的氨氮去除效果. 在一定的培养时 间内, 接种量过小, 菌株繁殖速度慢、数量少, 从而影响

氨氮去除效果. 从图 5a 可以看出, 在 $1 \% \sim 10 \%$ 的投菌量下,培养 $60 \mathrm{~h}$ 后, 随着投加量的增加, 菌株 Z 01 的细 胞生长量也增加, $10 \%$ 时达到最大. 当投菌量增加到 $15 \%$ 时, 菌株 Z 01 的细胞生长量反而有小幅度的下降, 其原因可能是, 在一定的培养时间内, 接种量过大, 菌株的初始数量基数大, 造成溶解氧不足, 引起生物竞争 而致使一些细菌死亡. 在 1\% 7\% 的投菌量情况下, 培养 $60 \mathrm{~h}$ 后, 随着投加量的增加, 菌株 Z 01 对氨氮的去 除率也增加, 并在 7\% 的投加量时达到最大, 为 $87.29 \%$. 而当投菌量继续增加到 $10 \%$ 时, 菌株 Z 01 的细胞生 长虽达到稳定期, 但氨氮去除率并未达到最大, 说明氨氮的去除不仅由细胞生长引起, 同时也与细胞代谢有 
关. 因此在实际操作中选择适当的投菌量对污水脱氮处理具有重要意义. 综合考虑, 本实验菌株 Z01 的最佳 投菌量为 $7 \%$.

不同微生物所需的碳源种类也有所区别, 如 Pseudomonas sp. XS76 可以利用丁二酸钠和柠檬酸钠进行 良好的硝化反应去除氨氮 ${ }^{[21]}$; Alcaligenes faecalis No.4 只能利用有机酸才能进行硝化反应, 从而去除氨氮 ${ }^{[23]}$. 从图 $5 \mathrm{~b}$ 可以看出, 菌株 Z 01 对 5 种碳源的利用程度和生长情况差异非常显著, 在以葡萄糖和柠檬酸钠为碳 源时, 菌株 Z01 的生长及氨氮去除性能较好, 尤其是添加碳源葡萄糖后, 菌株 Z01 对氨氮的去除率高达 86. $44 \%$. 在以乙酸钠为碳源的培养基中, 菌株 Z01 的生长量急剧减缓, 对氨氮的去除率也大幅度降低. 而在以 淀粉和蔗糖为碳源的培养基中, 菌株 Z01 几乎不生长, 对氨氮的去除率也极低, 仅为 $1.63 \%$, 这与王弘宇 等 ${ }^{[25]}$ 和潘丹 ${ }^{[21]}$ 等的研究结果相似, 可能与葡萄糖和柠檬酸钠作为前体物直接参与 TCA 循环有关. 本研究 中葡萄糖是菌株 Z01 异养硝化过程中的最佳碳源, 柠檬酸钠其次.
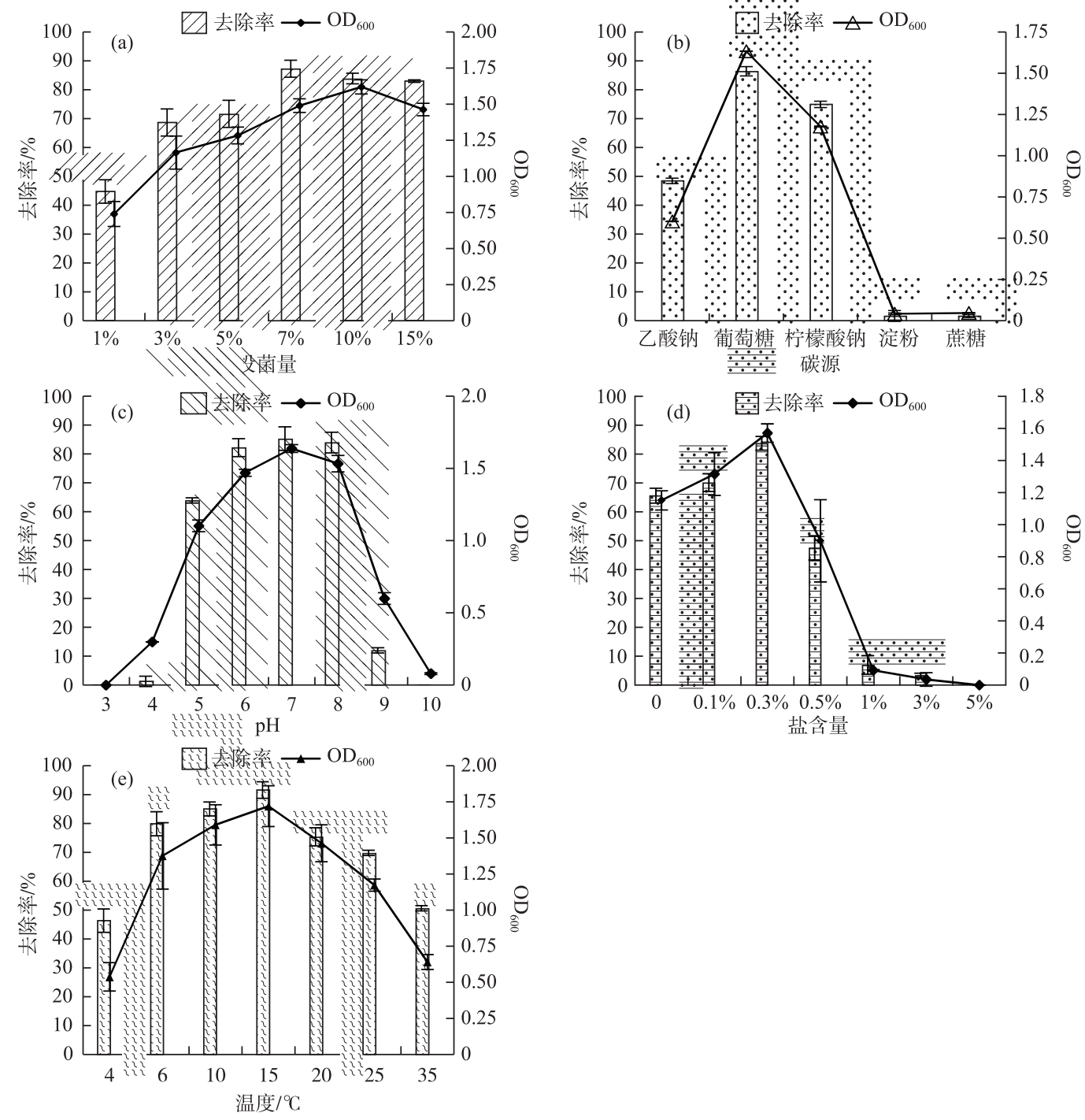

图 5 不同条件下菌株 Z01 对氨氮的去除特性

(当 $\mathrm{pH}$ 为 9 和 10 时,氨氮去除率是扣除了空白组氨氮的挥发率之后菌株 Z01 对氨氮的去除率)

Fig.5 The removal characterization of ammonia nitrogen by strain Z01 
环境中的 $\mathrm{pH}$ 值也是影响微生物生命活动的重要因素之一. $\mathrm{pH}$ 主要作用是能够引起细胞膜电荷的变 化, 进而影响微生物对营养物质的吸收. 此外, $\mathrm{pH}$ 值还影响微生物代谢过程中酶的活性, 改变生长环境中营 养物质的可给性及有害物质的毒性 ${ }^{[26]}$. 由图 5c 可知, 当 $\mathrm{pH}$ 值为 $6 \sim 8$ 时, 菌株 Z01 具有良好的氨化效果, 培 养 $60 \mathrm{~h}$ 后, 氨氮去除效率达 82.21\% 85.34\%. 在酸性 $(\mathrm{pH} \leqslant 4)$ 或碱性 $(\mathrm{pH} \geqslant 9)$ 条件下, 菌株生长状况都不 好, 基本没有氨化效果, 说明该菌并不能适应强酸和强碱性的环境. 若环境中的氢离子或氢氧根离子浓度超 过了微生物酶的适应范围, 微生物对营养物质的吸收和酶的活力都会受到影响. 因此菌株能够耐受的 $\mathrm{pH}$ 范 围为 $5 \sim 8$, 最佳 $\mathrm{pH}$ 为 $6 \sim 8$, 该菌在中性和弱碱性条件下氨氮去除效果显著.

盐度可以直接影响微生物的新陈代谢, 进而影响其硝化性能. 由图 $5 \mathrm{~d}$ 可知, 当 $\mathrm{NaCl}$ 浓度为 $0 \sim 0.3 \%$ 时, 随着盐浓度的增加, 菌株 Z01 生长量增加, 其对氨氮的去除率也有所提高. 当盐浓度为 $0.3 \%$ 时, 菌株 Z01 的 生长最好, 氨氮的去除率最高, 达 $83.74 \%$. 当 $\mathrm{NaCl}$ 浓度进一步提高到 $0.5 \% \sim 5.0 \%$ 时, 菌株 Z 01 的生长明显 减慢, 氨氮的去除率也急剧下降, 其可能原因是: 无机盐是生物细胞生长的一种必需元素, 适量的无机盐对 细胞具有积极作用, 如调节细胞渗透压、激活和调节生物酶的活性、合成细胞有机物的原料、调节细胞 $\mathrm{pH}$ 值 ${ }^{[27]}$. 如果培养液中盐不足, 微生物细胞生长就会受到抑制. 但相反, 如果盐浓度过高, 超过了细胞生长的 需求量,微生物的生长同样受到抑制,微生物细胞会脱水甚至死亡.

温度是影响微生物生长与存活的重要因素之一. 由图 $5 \mathrm{e}$ 可知, 菌株 $\mathrm{Z} 01$ 在 $6 \sim 25^{\circ} \mathrm{C}$ 范围内均生长良好, 在 $15^{\circ} \mathrm{C}$ 时 $\mathrm{OD}_{600}$ 值达到最大值, 为 1.722 , 氨氮的去除效率高达 $91.66 \%$. 随着温度的升高或降低, 菌悬液的 $\mathrm{OD}_{600}$ 值 都会降低, 氨氮的去除效率也随着下降. 因此, 菌株 $\mathrm{Z} 01$ 的最适温度为 $15^{\circ} \mathrm{C}$. 菌株在不同温度下生长情况的差 异在于: 温度影响细胞内酶的活性, 改变细胞内蛋白质、核酸等生物大分子的结构与功能以及细胞的结构如细 胞膜的流动性及完整性, 从而影响微生物的生长、繁殖和新陈代谢 ${ }^{[28]}$. 过高的温度导致蛋白质或核酸的变性失 活,而过低的温度可严重影响生物处理的传质速率及微生物的生长代谢,进而降低菌株的氨化性能.

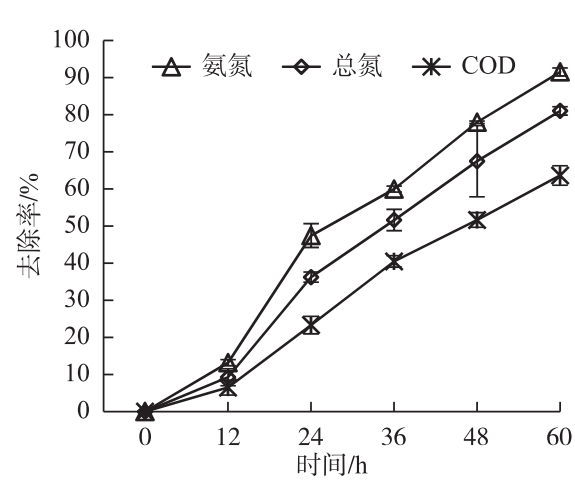

图 6 菌株 Z01 在最适条件下对模拟废水 中氨氮、总氮和 COD 的去除率

Fig. 6 The removal rates of $\mathrm{NH}_{3}-\mathrm{N}$,

$\mathrm{TN}$ and COD in polluted water by strain $\mathrm{ZO1}$ at its best conditions

\section{5 菌株 Z01 在最适条件下的去除率}

菌株 Z01 在最适条件下对人工模拟废水中氨氮、总氮、 COD 的去除率见图 6. 当菌株 Z01 投菌量为 7\% 时, 在温度为 $15^{\circ} \mathrm{C}, \mathrm{pH}$ 为 $6 \sim 8$, 盐度为 $0.3 \%$, 最佳碳源为葡萄糖的条件 下,第 $60 \mathrm{~h}$ 模拟废水中氨氮的去除率高达 $91.57 \%$, 约为最初 去除率的 1.1 倍. 同时, 菌株 Z01 对模拟废水中总氮和 COD 也有较好的去除, 其去除率分别为 $81.07 \%$ 和 $63.67 \%$. 由此 可见, 菌株 Z01 能很好地利用废水中营养物质进行硝化作 用, 甚至是一定的反硝化作用, 具体的有机物代谢及反硝化 机理有待进一步研究.

通过对菌株 Z01 在最适条件下的脱氮活性进行鉴定, 发现菌株 10 不仅脱氮效果明显, 且脱氮时间大大缩短. 刘 芳芳等 ${ }^{[29]}$ 报道的 4 株粪产碱杆菌 (Alcaligenes faecalis) 79、 84 、 L116 和 L117 经 $48 \mathrm{~h}$ 对氨氮的去除率分别达到 $44.4 \%$ 、 $47.9 \% 、 61.3 \%$ 和 $56.4 \%$. 李晓亮 ${ }^{[30]}$ 笁选到的菌株 R $14-Z Y-5$ 和 CC6-YY-74 以 $4 \%$ 的接种量于 $10^{\circ} \mathrm{C} 、 120$ 转/ $\mathrm{min}$ 振荡培 养, 在 $96 \mathrm{~h}$ 内 氨氮去除率达 $83.31 \%$ 和 $82.82 \%$. 王宏宇等 ${ }^{[24]}$ 分离到的异养硝化细菌 Pseudomonas sp. ZW2 和 Alcaligenes faecali ZW5 经 $60 \mathrm{~h}$ 培养对氨氮去除率分别为 43.90\% 和 48.52\%. 因而可以认定本实验分离笁选 的菌株 Z01 是一株高效低温异养硝化菌. 辛玉峰等 ${ }^{[31]}$ 发现的 Acinetobacter sp. YF14 对氨氮去除率可以达到 $92 \%$, 但该菌株所需的硝化时间长达 3 d. Paracoccus denitrificans FJAT-14899 不仅氨氮去除率高, 且其硝化时 间仅需 $12 \mathrm{~h}$.

\section{3 结论}

1 ) 从冬季南四湖人工湿地底泥中分离出 5 株生长较好且具有一定硝化性能的耐冷菌, 并从中䇥选出一 
株氨化效率最高的菌株, 其氨氮去除效率高达 $83.51 \%$. 经鉴定该菌株为假单胞菌属 (Pseudomonas sp.), 命名 为 Pseudomonas sp. Z01.

2) 分别对影响菌株的生长条件如生长时间、初始投菌量、 $\mathrm{pH}$ 、盐度、碳源、温度进行了研究,得到该菌株 的最适生长条件: 培养时间为 $60 \mathrm{~h}$, 初始投菌为 $7 \%, \mathrm{pH}$ 为 $6.0 \sim 8.0$, 盐度 $0.3 \%$, 温度 $15^{\circ} \mathrm{C}$, 最佳碳源为葡 萄糖.

3) 在最适生长条件下,该菌株对模拟污水中的氨氮、总氮和 COD 均有较好的去除效果.

\section{4 参考文献}

[ 1 ] Xia S, Li J, Wang R. Nitrogen removal performance and microbial community structure dynamics response to carbon nitrogen ratio in a compact suspended carrier biofilm reactor. Ecological Engineering, 2008, 32(3) : $256-262$.

[ 2 ] Bai SN, Xu TY, Liu Y et al. Separation and selection of heterotrophic nitrifying bacteria from lawn soil and their nitrification products characteristics. Acta Horticulturae Sinica, 2018, 45(7)：1338-1346. [白三女, 许天月, 刘英等. 草坪土 壤异养硝化菌的分离篮选及硝化产物特征分析. 园艺学报, 2018, 45(7): 1338-1346.]

[ 3 ] Yao S, Ni JR, Ma T et al. Heterotrophic nitrification and aerobic denitrification at low temperature by a newly isolated bacterium Acinetobacter sp. HA2. Bioresource Technology, 2013, 139: 80-86.

[ 4 ] Wang J, Lan JL, Liu B. Isolation and denitrification characteristics of a heterotrophic nitrification bacterium. Journal of Agro-Environment Science, 2013, 32(4)：805-810. [王洁, 蓝江林, 刘波. 一株异养硝化细菌的分离鉴定和脱氮特 性研究. 农业环境科学学报, 2013,32(4) : 805-810.]

[ 5 ] Tian FR, Zhang BB, Yang ZL et al. Isolation, identification of heterotrophic nitrifiers and optimization of their ammonia nitrogen removal efficiency. Environmental Engineering, 2014, 32(5): 64-68. [田凤蓉, 张涁涁, 杨志林等. 高效脱氨 除臭异养硝化菌的耖选鉴定及脱氨性能研究. 环境工程, 2014, 32(5): 64-68.]

[ 6 ] Li XL, Zhang L, Zhang PY et al. Screening, biodiversity, and growth characteristics of cold-adapted nitrobacteria isolated from Arctic Ocean sediments. Chin J Appl Environ Biol, 2017, 23(2) : 294-300. [李晓亮, 张良, 张培玉等. 北极海洋 沉积物低温硝化细菌的䇻选、多样性与生长特性. 应用与环境生物学报, 2017, 23(2): 294-300.]

[ 7 ] Wang TY, Wei HF, Hu ZQ et al. Isolation and identification of a heterotrophic nitrifying and aerobic denitrifying strain and its denitrification characteristics. Acta Scientiae Circumstantiae, 2017, 37(3): 945-953. [王田野, 魏荷芬, 胡子全等. 一株异养硝化好氧反硝化菌的笁选鉴定及其脱氮特性. 环境科学学报, 2017, 37(3): 945-953.]

[ 8 ] Lin Y, Kong HN, He YL et al. Isolation and characterization of heterotrophic nitrifying bacteria. Environmental Science, 2006, 27(2) : 324-328. [林燕, 孔海南, 何义亮等. 异养硝化细菌的分离及其硝化特性实验研究. 环境科学, $2006,27(2): 324-328$.

[ 9 ] Zhao $\mathrm{B}$, An Q, He YL et al. $\mathrm{N}_{2} \mathrm{O}$ and $\mathrm{N}_{2}$ production during heterotrophic nitrification by Alcaligenes faecalis strain NR. Bioresource Technology, 2012, 116: 379-385.

[10] Kundu P, Pramanik A, Mitra S et al. Heterotrophic nitrification by Achromobacter xylosoxidans S18 isolated from a smallscale slaughterhouse wastewater. Bioprocess and Biosystems Engineering, 2012, 35(5) : 721-728.

[11] Li B, Zhang QF, Dou SH et al. Screening of a psychrotrophic oil-degrading strain LHB16 and its degradation characteristics. Biotechnology, 2010, 20(5):83-85. [李兵, 张庆芳, 窦少华等. 低温石油降解菌 LHB16 的笁选及降解特性研 究. 生物技术, $2010,20(5): 83-85$.]

[12] Yan FJ, Tian XL, Dong SL et al. Isolation, identification and characterization of a low-temperature degrading bacterium. Periodical of Ocean University of China, 2011, 41(3) : 24-30. [国法军, 田相利, 董双林等. 一株低温去除菌的分离 鉴定及其去除特性研究. 中国海洋大学学报, 2011, 41(3) : 24-30.]

[13] Zhao Y. Separation and identification of psychrotrophic ammonia degradation bacteria and their applications in wastewater treatment [Dissertation]. Lanzhou: Lanzhou Jiaotong University, 2013. [赵燕. 耐冷氨氮降解菌的分离、鉴定及其在废 水处理中的应用研究 [学位论文]. 兰州: 兰州交通大学, 2013.]

[14] Chevalier P. Nitrogen and phosphorus removal by high latitude mat- forming cyanobacteria for potential use in tertiary wastewater treatment. Applied Phycology, 2000, 12(2) :105-113.

[15] Xu Q, Zhu GB, Du GC. Separation and identification of an efficient psychrotrophic bacteria and research on its degradation characteristics. Chinese Journal of Environmental Engineering, 2010, 4(2): 377-382. [徐巧, 诸葛斌, 堵国成. 一株高 
效耐冷菌的分离鉴定及去除特性研究. 环境工程学报, 2010, 4(2): 377-382.]

[16] Zou YX. Enhance ammonia removal effect in constructed wetland at low temperature [Dissertation]. Changchun: Jilin University, 2014. [邹雨璇. 低温条件下人工湿地氨氮强化脱氮机理的研究 [学位论文]. 长春: 吉林大学, 2014.]

[17] Cheng Y, Li QF, Fei YT et al. Screening and nitrogen removing characteristics of heterotrophic nitrification-aerobic denitrification bacteria SLWX2 from sea water. Environmental Science, 2016, 37(7): 2681-2688. [成钰, 李秋芬, 费聿涛等. 海水异养硝化-好氧反硝化芽狍杆菌 SLWX2 的笁选及脱氮特性. 环境科学, 2016, 37( 7) : 2681-2688.]

[18] Zhou DQ ed. Microbiology experiment course: The third edition. Beijing: Higher Education Press, 2013. [周德庆. 微生 物学实验教程: 第三版. 北京: 高等教育出版社, 2013.]

[19] Dong XZ, Cai MY eds. Manual of identification in common bacteria system. Beijing: Science Press, 2001: 364-379. [ 东 秀珠, 蔡妙英. 常见细菌系统鉴定手册. 北京: 科学出版社, 2001: 364-379.]

[20] Editorial board of "Water and wastewater monitoring and analysis method", Ministry of Environmental Protection of the People's Republic of China ed. Monitoring and analysis methods of water and wastewater: fourth edition. Beijing: China Environmental Science Press, 2002. [ 国家环境保护总局《水和废水监测分析方法》编委会. 水和废水监测分析方 法: 第 4 版. 北京: 中国环境科学出版社, 2002.]

[21] Pang D, Peng ZR, He WH et al. Screening, identification and immobilized optimization of heterotrophic nitrifying bacteria. Genomics and Applied Biology, 2018, 37(6) : 2430-2437. [庞朵, 彭自然, 何文辉等. 异养高效硝化细菌的筛选鉴 定与固定化最优化. 基因组学与应用生物学, 2018, 37(6): 2430-2437.]

[22] He TX, Ni JP, Li ZL et al. Heterotrophic nitrification and aerobic denitrification of the hypothermia aerobic denitrification bacterium: Arthrobacter arilaitensis. Environmental Science, 2016, 37(3):296-302. [何腾霞, 倪九派, 李振轮等. 1 株 Arthrobacter arilaitensis 菌的耐冷异养硝化和好氧反硝化作用. 环境科学, 2016, 37(3) : 296-302.]

[23] Buchanan RE, Gibbons NE eds. Bergey's manual of systematic bacteriology: Eight edition. Baltimore: The Williams \& Wilkins Company, 1974.

[24] Joo HS, Hirai M, Shoda M. Characteristics of ammonium removal by heterotrophic nitrification-aerobic denitrification by Alcaligenes faecalis no. 4. Journal of Bioscience and Bioengineering, 2005, 100(2) : 184-191.

[25] Wang HY, Ma F, Yang K et al. Ammonia removal by two strains of heterotrophic nitrifying bacteria. China Environmental Science, 2009, 29(1) : 47-52. [王弘宇, 马放, 杨开等. 两株异养硝化细菌的氨氮去除特性. 中国环境科学, 2009, $29(1): 47-52$.

[26] Gupta AB. Thiosphaera pantotropha a sulphur bacterium capable of simultaneous heterotrophic nitrification and aerobic denitrification. Enzyme and Miicrobial Technology, 1997, 21(8) : 589-595.

[27] Tang MZ, Li TT, Wang YN et al. Identification and characterization of an efficient psychrotrophic bacterial strain isolated from artificial wetlands. Acta Scientiae Circumstantiae, 2013, 33(3): 708-714. [唐美珍, 李婷婷, 王艳娜等. 人工湿地 中一株高效低温菌的分离鉴定与去除特性研究. 环境科学学报, 2013, 33(3) : 708-714.]

[28] Zhu F, Wang S, Zhou PJ. Molecular mechanisms of cold-adapted enzymes to cold environment and their application in biotechnology industry. Acta Microbiologica Sinaca, 2002, 42(5):640-664. [ 朱非, 王珊, 周培瑾. 低温酶冷适应的分子 机制及其在生物技术中的应用. 微生物学报, 2002, 42(5): 640-644.]

[29] Liu FF, Zhou DP, Wu SH et al. Isolation and identification of heterotrophic nitrifiers from cultivation wastewater. Journal of Agro-Environment Science, 2010, 29(11) : 2232-2237. [刘芳芳, 周德平, 吴淑杭等. 养殖废水中异养硝化细菌的 分离篮选和鉴定. 农业环境科学学报, 2010, 29(11): 2232-2237.]

[30] Li XL. Screening of cryogenic nitrification bacteria and its preliminary application in a low temperature wastewater treatment [Dissertation]. Qingdao: Qingdao University, 2017. [李晓亮. 低温硝化细菌的篮选及其在低温污水处理中的初步应 用研究 [学位论文]. 青岛: 青岛大学, 2017.]

[31] Xin YF, Qu XH, Yuan MD et al. Isolation and identification of a nitrifying and aerobic denitrifying Acinetobacter sp. YF14 and its denitrification activity. Acta Microbiologica Sinica, 2011, 51(12)：1646-1654. [辛玉峰, 曲晓华, 袁梦东等. 一 株异养硝化-反硝化不动杆菌的分离鉴定及脱氮活性. 微生物学报, 2011, 51(12): 1646-1654.] 